\title{
Strengthening mutual accountability and \\ performance in agriculture in Southern Africa
}

AUTHORS:

Charles Nhemachena ${ }^{1}$

Greenwell Matchaya ${ }^{1}$

Sibusiso Nhlengethwa ${ }^{1}$ iD

\section{AFFILIATION:}

1International Water Management Institute, Pretoria, South Africa

\section{CORRESPONDENCE TO:}

Charles Nhemachena

\section{EMAIL:}

CNhemachena@gmail.com

\section{DATES:}

Received: 25 June 2016

Revised: 10 0ct. 2016

Accepted: 24 Jan. 2017

\section{KEYWORDS:}

joint sector review; CAADP; agriculture; ReSAKSS; monitoring \& evaluation

\section{HOW TO CITE:}

Nhemachena C, Matchaya G, Nhlengethwa S. Strengthening mutual accountability and performance in agriculture in Southern Africa. S Afr J Sci. 2017;113(5/6), Art. \#2016-0185, 7 pages. http://dx.doi.org/10.17159/ sajs.2017/20160185

\section{ARTICLE INCLUDES: \\ $\times$ Supplementary material \\ $\times$ Data set}

\section{FUNDING:}

ReSAKSS receives funding from USAID; UK Department for International Development (DFID); Swedish International Development Cooperation Agency (Sida); Bill \& Melinda Gates Foundation; International Fund for Agricultural Development (IFAD); Ministry of Foreign Affairs of the Netherlands (MFAN)
We critically assessed experiences in the implementation of agricultural joint sector reviews in supporting mutual accountability in Southern Africa, focusing on the lessons learned, the challenges and recommendations for improvement. Empirical data were gathered from four countries that have implemented joint sector reviews: Malawi, Mozambique, Swaziland and Zambia. The results show that recent efforts to conduct joint sector review assessments in these countries have raised the quest for increased accountability for action and results. Despite progress to strengthen mutual accountability in the countries, monitoring and evaluation capacity remains a concern, especially at sub-national levels. The mutual accountability process and implementation of the agricultural joint sector review processes in the respective countries have come a long way in facilitating sector-wide engagement of stakeholders in planning, implementation and monitoring and evaluation of agricultural policies and programmes. These processes are critical to ensure effective implementation and realisation of development impacts of agricultural priorities in the national agricultural investment plans.

\section{Significance:}

- The implementation of the CAADP mutual accountability framework is critical to ensure effective implementation and realisation of development impacts of agricultural priorities in the national agricultural investment plans.

- Agriculture joint sector reviews facilitate sector-wide engagement of stakeholders in planning, implementation, and monitoring and evaluation of agricultural policies and programmes.

\section{Introduction}

There are various international initiatives that aim to improve aid effectiveness, including the 2005 Paris Declaration, the 2008 Accra Agenda for Action and the 2011 Busan Partnership for Effective Development Co-operation. These initiatives focus on improving aid effectiveness through better alignment, harmonisation, results reporting and monitoring, among other objectives. Despite the slow progress towards mutual accountability in the 2008 progress report on implementing the Paris Declaration compared to other principles of the declaration, several initiatives - such as forums for debates, peer reviews and arrangements - have been developed to strengthen mutual accountability and oversee performance between donors and partners. ${ }^{1}$ The 2011 Busan Global Partnership for Effective Development Co-operation embraced the commitments set out in the 2005 Paris Declaration and 2008 Accra Agenda for Action to implement efforts aimed at enhancing effectiveness of development partnerships. ${ }^{2,3}$ In strengthening mutual accountability, the Global Partnership for Effective Development Co-operation (which followed the Busan Partnership) reaffirmed the commitment to jointly assess country systems based on mutually agreed diagnostic tools. Strengthening mutual accountability for development results through creating and reinforcing shared agendas and strengthening partnerships, among others, helps ensure that complementary efforts in development are transparent and results focused. ${ }^{1}$

The African Heads of State and Government adopted the 2014 Malabo Declaration on Accelerated Agricultural Growth and Transformation for Shared Prosperity and Improved Livelihoods which reaffirmed the commitments of the 2003 Maputo Declaration and resolved additional commitments and targets with heightened emphasis on implementation, results and impacts. In line with the international resolutions on aid effectiveness, such as the 2005 Paris Declaration, the 2008 Accra Agenda for Action and the 2011 Busan Global Partnership; the Malabo Declaration's commitment to accountability stresses the continent's resolve to strengthen achievement of results anchored with effective and efficient implementation capacity and optimisation of resources. ${ }^{4}$ The seventh commitment of the 2014 Malabo Declaration focuses on strengthening mutual accountability to actions and results through a systematic regular review process guided by the Comprehensive Africa Agriculture Development Programme (CAADP) Results Framework. ${ }^{4,5}$ The CAADP Implementation Strategy and Roadmap identifies the Agricultural Joint Sector Review as the principal instrument for operationalising the mutual accountability framework and reporting on agreed commitments while serving as a good platform to discuss implementation. ${ }^{4}$

Monitoring and evaluation of agricultural development programmes and policies remains one critical area requiring support among African countries in their implementation of the CAADP programme. To strengthen mutual accountability for results and provide evidence-based support to agricultural policy/programme planning and implementation, current monitoring and evaluation systems need to be improved in most countries on the continent. This monitoring and evaluation is critical to ensure that the requirements of accountability to commitments and results, as well as learning from the Malabo Declaration and CAADP Mutual Accountability Framework, are satisfied. Despite progress made in implementing agricultural joint sector reviews (JSRs) in Southern Africa, there have been no efforts to provide a systematic, regional review of the experiences in terms of lessons learned, analysis of the challenges and recommendations for improvement. In this paper, we use experiences from the implementation of JSRs in Malawi, Mozambique, Swaziland and Zambia in an effort to fill this empirical gap. 


\section{Background}

The 2014 Malabo Declaration commits the African heads of states and government to strengthening mutual accountability for actions and results by promoting evidence-based agricultural policy planning and implementation processes through peer review, dialogue, benchmarking and the adoption of best practices. ${ }^{5}$ The African Union Commission, NEPAD Planning and Coordinating Agency, regional economic communities, country stakeholders and development partners regard the improvement of country policy processes as critical to ensure successful implementation of national agriculture and food security investment plans and advance the CAADP agenda. The African Union Commission and NEPAD Planning and Coordinating Agency adopted the Mutual Accountability Framework which sets the principles for mutual review and the CAADP Results Framework which identifies priority areas and performance indicators for tracking targets in the Malabo Declaration.

Agricultural JSRs are a key instrument for supporting mutual accountability and implementing the CAADP Results Framework. The JSRs collectively review the effectiveness of policies and institutions in the agriculture sector, as well as the extent to which intended results and outcomes in the sector are being realised. Overall, the JSR processes are expected to serve as a management and policy support tool for inclusive stakeholder planning, programming, budget preparation and execution, monitoring and evaluation, and overall development of the agriculture sector by allowing a broad spectrum of stakeholders to gain insights into and influence the sector's overall policies and priorities. ${ }^{6}$

The JSRs implemented in the agriculture sector have focused on: (1) policy and institutional reviews, (2) a review of progress toward sector results and outcomes and (3) a review of the status and quality of the JSR process in the country. The policy and institutional reviews focused on the coherence, consistency and adequacy of the policy mix and institutional architecture in ensuring successful implementation of national agriculture and food security investment plans. The focus of the second objective was on measuring progress made toward targeted results and declared commitments, including key agriculture sector targets, such as growth, productivity, and other major results defined in national agriculture and food security investment plans and other policy and programme documents. This objective included a review of budgetary allocations, investments, financial support, capacity building, and organisational commitments made by governments, donors and non-state actors. The third objective focused on identifying actions to address the gaps and weaknesses in the sector review process, in terms of technical and institutional capacity, and to promote best practices in those processes. ${ }^{6}$ This background provides the analytical framework applied in this paper to review progress of the experiences of implementation of agricultural sector JSRs in Southern Africa.

\section{Methodology and data}

The paper is based on data gathered from JSR assessments conducted by the Regional Strategic Analysis and Knowledge Support System (ReSAKSS) of Southern Africa in Malawi, Mozambique, Swaziland and Zambia. The analysis of the experiences and lessons learned from the JSR assessments in Southern Africa was conducted within the framework of the JSRs facilitated by ReSAKSS and the International Food Policy Research Institute in supporting the strengthening of the CAADP Mutual Accountability Framework. The data collection process for the JSR process in the respective countries was based on the following approach. The process mainly relied on qualitative methods for gathering required data. These methods included an extensive review of the literature targeting the respective country's main development strategy frameworks including key agricultural sector policies. JSR reports from other countries were also reviewed to provide lessons in implementation of JSRs in the Southern Africa region. In addition to reviewing literature, the most knowledgeable stakeholders were engaged to gather data and other important documents for review in each of the countries. The stakeholders engaged were identified during the inception meetings of the JSR processes and engagements with the respective Ministries of
Agriculture. The stakeholders engaged ranged from government officials (particularly in the Ministries of Agriculture and Finance), development partners, private sector representatives, civil society organisations and representatives of farmer organisations. The engagements were mainly in the form of semi-structured interviews with the identified respondents. The information gathered was collated and analysed for the respective sections of the JSR report for each country. The data collected and analysed were validated together with the national JSR report for each country at an agriculture sector-wide validation workshop that provided a platform for stakeholders to externally review the report and data before the report was finalised.

The analysis in this paper is guided by the focus of the JSR assessments conducted in the study countries which aimed at collectively reviewing the effectiveness of policies and institutions in the agricultural sector, the status and quality of the agricultural JSR process itself, and the extent to which intended results and outcomes in the sector were being realised. We provided technical support in the planning, implementation and review of the JSR assessments in these countries, which provided us with a better perspective of the JSR assessment processes and outcomes in all the study countries.

The JSR assessments in Malawi and Mozambique were conducted at least twice (including non-alliance and Grow Africa annual reporting). In Swaziland and Zambia, JSR assessments were conducted in 2015. The two sets of countries provide a unique combination of two countries that have advanced in implementing JSRs (namely Malawi and Mozambique) and two which have conducted maiden JSR assessments in the agricultural sector (Swaziland and Zambia). Although the findings focus on JSR experiences in the agricultural sector in Southern Africa, the discussions of the findings can be of interest to other sectors and countries both in the region and elsewhere in Africa.

\section{Results and discussion}

Experiences in the implementation of agricultural JSRs in support of mutual accountability in the focus countries (Malawi, Mozambique, Swaziland and Zambia) were analysed according to an assessment of the lessons learned, the challenges experienced and recommendations made for improvement. The subsequent analysis and discussion is structured around experiences on: status and quality of agricultural JSRs assessments; policy and institutional reviews; financial and nonfinancial commitments; and monitoring and evaluation.

\section{Experiences on the status and quality of agricultural JSRs}

The selected countries are at different stages in terms of implementing the CAADP agenda. Table 1 summarises the agricultural JSR or similar activities of each country. Malawi and Mozambique have significantly advanced in implementing their National Agricultural Investment Plans while Zambia and Swaziland are at the initial phases of operationalising their investment plans. Findings from the four countries indicate that each country has some kind of agricultural sector monitoring and evaluation intervention (or review) that has been instituted to track progress and or encourage sector-wide engagements with stakeholders. For example, Malawi, in their first JSR report in 2014, reported that the country had JSRs focused on tracking performance of the Agricultural Sector-Wide Approach Programme.? Mozambique reported the existence of the Programmatic Aid Partners dialogue platform which annually evaluates the effectiveness of donor's aid, including reviewing commitments and performance indicators. ${ }^{8}$ Both Malawi and Mozambique have signed cooperation agreements with the Group of Eight (G8) New Alliance for Food Security and Nutrition, which was launched in April 2013, and Mozambique has entered an agreement with the Agricultural Development Policy Operation - a project of the World Bank. The New Alliance is a shared commitment by the respective governments, private sector and development partners to achieve sustained and inclusive agricultural growth. As members of the New Alliance Cooperation Agreement, both countries have to produce annual reports on progress made on achievements. To date they have produced New Alliance reports for 2014 and 2015. 
Zambia and Swaziland indicated a different status with respect to agricultural JSRs. Zambia, for instance, had an agricultural JSR during the Agricultural Sector Investment Programme (ASIP) between 1996 and 2000. ${ }^{9}$ These reviews were discontinued when the Agricultural Sector Investment Programme was phased out and they have been conducting ad hoc reviews of agricultural sector programmes and or projects mainly driven by development partners. Since finalisation of the National Agricultural Investment Plan and drafting of the national Joint Sector Review Roadmap with support from the European Union, Zambia has been setting up structures to revive agricultural JSRs. The 2015 JSR report for Zambia combined efforts from what the country was already doing as indicated in their JSR roadmap and the African Union/ ReSAKSS JSR support for member states. Swaziland, on the other hand, implemented her maiden JSR report in 2015 supported by ReSAKSS Southern Africa. The country had had only agricultural sector reviews consisting of ministerial quarterly reports submitted to parliament and reports of performance targets to the office of the Prime Minister. ${ }^{10}$

The findings also showed that, through conducting the agricultural JSRs, these four countries realised and/or revived the need to institute the implementation of the JSR as a way of enhancing mutual accountability of action and results. In a separate study, Holvoet and Inberg ${ }^{11}$ - based on experiences from the education sectors in Burkina Faso, Mali and Niger found that JSRs facilitated harmonisation, coordination, leadership and wide stakeholder participation and prioritised accountability. Evidence from the current study also indicates the important contribution of the JSR processes in the respective countries. For example, Swaziland has expressed an interest to implement the action plan from the $2015 \mathrm{JSR}$ process and is also setting up monitoring and evaluation structures to coordinate the evaluation of agricultural sector activities, including ensuring that credible and adequate data are available. Malawi has advanced in implementing their annual agricultural sector review which now starts with planning at the beginning of the year and a review of performance at the end of the year (around October/November). Mozambique has stepped up efforts to develop indicators for tracking commitments and performance of the implementation of their national agricultural investment plan (PNISA).

\section{Experiences on policy and institutional reviews}

The policy reviews showed that within each of the four countries, there were a number of agricultural policies addressing various aspects in the sector. Table 2 summarises the ratings on progress on institutional and policy actions. Although the policies were rated adequately in covering priority issues in the agricultural sector in the different countries (see Table 2), the main challenge was that, in some cases, these policies were not harmonised to clearly complement each other. Furthermore, it was reported that, although some of these policies were adequate 'on paper', they were not being implemented. For instance, the main

Table 1: Joint sector review (JSR) assessment activities in the focus countries

\begin{tabular}{l|l|l}
\hline \hline \multicolumn{1}{c|}{ Country } & \multicolumn{1}{c|}{ JSR assessment } & \multicolumn{1}{c}{ Other sector review activities for advancing mutual accountability } \\
\hline Malawi & $\begin{array}{l}\text { JSR }(2014) ; \text { New Alliance } \\
\text { Report }(2014 ; 2015)\end{array}$ & $\begin{array}{l}\text { Agriculture sector status report; Technical Working Groups (e.g. on monitoring and evaluation); Sectoral Working } \\
\text { Group }\end{array}$ \\
\hline Mozambique & $\begin{array}{l}\text { JSR }(2014) ; \text { New Alliance } \\
\text { Report }(2014 ; 2015)\end{array}$ & $\begin{array}{l}\text { Agriculture Development Operation with World Bank; Programmatic Aid Partners dialogue platform; Technical } \\
\text { Working Groups; Agriculture Sector Coordination Committee }\end{array}$ \\
\hline Zambia & JSR (2015) & National JSR roadmap; Agricultural Sector Advisory Group; Special Stakeholder meetings called by the Minister \\
\hline Swaziland & JSR (2015) & $\begin{array}{l}\text { Ad hoc ministerial reports to parliament and quarterly reports to the Office of the Prime Minister on performance } \\
\text { targets; donor-driven programme evaluations }\end{array}$ \\
\hline
\end{tabular}

Sources: JSR reports from each country ${ }^{7-10}$

Table 2: $\quad$ Summary ratings on the implementation of policy dimensions

\begin{tabular}{|c|c|c|c|c|}
\hline \multirow{2}{*}{ Policy dimension } & \multicolumn{4}{|c|}{ Traffic light rating } \\
\hline & Malawi & Mozambique & Swaziland & Zambia \\
\hline Quality of policy planning and execution & Green & Green & Amber & Amber \\
\hline Consistency of policy mix & Amber & Amber & Amber & Amber \\
\hline Alignment of NAIP with policies & Green & Green & Amber & Green \\
\hline Policy implementation status & Amber & Amber & Red & Amber \\
\hline Adequacy of policy coverage & Amber & Amber & Green & Amber \\
\hline
\end{tabular}

Green indicates that the commitment has been achieved to a reasonable degree; amber that the commitment has been partly achieved but additional attention is required; and red that the commitment has not yet been achieved.

NAIP, National Agriculture Imagery Program 
challenge in Swaziland was that agricultural policies usually did not have clear targets or implementation, monitoring and evaluation plans. ${ }^{10}$ In some cases, such as in Malawi, there is no overarching agricultural policy to guide investments and implementation of priorities in the sector, despite the country having many agricultural sector policy commitments and frameworks. ${ }^{7}$ In Mozambique, the various policies and strategies are influenced by long-term standing development goals and immediate crises and challenges which the country faces. ${ }^{8}$

The other key findings with agricultural policies was that they tended to be centralised to the respective ministry and higher offices of government with no sector-wide stakeholder engagements, such as in Mozambique and Swaziland. In such cases, the development, implementation, monitoring and evaluation of agricultural policies becomes the role of the respective ministry or central government, sometimes involving only a few development partners. However, in Mozambique for example, the development of the Strategic Plan for Agricultural Sector Development in 2011 was reported to have followed a participatory approach (involving government institutions, farmer organisations, private sector, development partners and civil society). This together with implementation of the CAADP process has helped improve participation of sector-wide stakeholders in policy planning and implementation processes. In contrast, Zambia reported that their processes from identifying policy gaps, policy development, planning and implementation involved wide stakeholder engagements. ${ }^{9}$ Overall, key lessons learned from the experiences include the need to ensure that agricultural policies are harmonised and complement each other clearly to enhance their planned impact. Also, these monitoring efforts help contribute to revising agricultural sector policies reflecting the priority needs in each country as elaborated through sector engagements. Engagement of all sector stakeholders is critical to facilitate transparency and accountability for action and results.

In all four countries, the respective ministries of agriculture are responsible for leading the agricultural JSR processes. The planning, implementation and (sometimes) monitoring and evaluation involved various departments and government agencies as well as nonstate actors. However, institutional involvement in agricultural sector stakeholder engagements varies from country to country. The main issues regarding institutional review were the lack of coordination within and among different institutions, lack of institutional implementation capacity and lack of participation of non-state actors (see Table 3 which illustrates ratings from experiences in the four countries). In Swaziland, some of the stakeholders, especially the non-state actors (the private sector, farmer organisations, civil society, etc.), reported that the engagements in agricultural sector policy/programme planning was superficial - usually only to 'rubber stamp' what the government and development partners had already decided and agreed on. ${ }^{10}$ Non-state actors' participation was rated better for their involvement in policy and programme formulation compared to that for implementation. However, active involvement of non-state actors in monitoring and evaluation of progress from the different agricultural policies and programme would be more effective if they were involved during the implementation phase as well.

The findings with regard to ratings in Table 3 show that in Malawi, Mozambique and Swaziland, coordination within government institutions was rated as 'Red'. The same rating applied for involvement of non-state actors in policy/programme planning and implementation in Swaziland; and institutional implementation capacity (especially monitoring and evaluation capacity) in Mozambique and Swaziland. The different reports indicated lack of coordinated efforts, especially within government institutions. Despite the presence of some structures for different ministries to mutually engage on various issues, it was noted that most of the respective designated officials failed to participate (for example in Malawi and Swaziland) and government ministries and departments continued to work in silos most of the time. Institutional implementation capacity was reported to be one of the critical areas requiring strengthening, especially in Mozambique and Swaziland. For example, in Mozambique the argument was that most of the implementation was being done with the support of international organisations and there was a critical need to have local institutional capacity strengthened. ${ }^{8}$

Table 3: Summary of ratings of institutional dimensions in the four countries

\begin{tabular}{|c|c|c|c|c|}
\hline \multirow{2}{*}{ Institutional dimension } & \multicolumn{4}{|c|}{ Traffic light rating } \\
\hline & Malawi & Mozambique & Swaziland & Zambia \\
\hline Coordination within government institutions & Red & Red & Red & Amber \\
\hline Participation of non-state actors in policy and programme & Green & Green & Amber & Green \\
\hline $\begin{array}{l}\text { Participation of non-state actors in policy and programme } \\
\text { implementation }\end{array}$ & Amber & Amber & Red & Amber \\
\hline Institutional alignment with the NAIP & Amber & Green & Amber & Green \\
\hline Institutional implementation capacity & Amber & Red & Red & Amber \\
\hline Coordination among development partners & Amber & Green & Amber & Green \\
\hline
\end{tabular}

Green indicates that the commitment has been achieved to a reasonable degree; amber that the commitment has been partly achieved but additional attention is required; and red that the commitment has not yet been achieved.

NAIP, National Agriculture Imagery Program 
This is a very typical governance problem in almost all countries in Southern Africa, although some countries have made special efforts to overcome the 'silo' problem. In some cases the 'silo' problem had entrenched itself: departments were functioning as dynasties beholden to their ministers; there was an organisational culture of jealousy and suspicion; and officials did not understand that developmental problems typically require different sectors. Overall, this is a complex issue that requires further detailed qualitative research to unpack it.

Evidence from the different JSR reports in the four countries indicates that the implementation of the CAADP agenda has encouraged agricultural sector stakeholders to engage with one another. However, gaps were reported in terms of effective engagement and consultation with all sector stakeholders. In all four countries, it was clear that most of the engagements were among government ministries, agents and development partners. Non-state actors - especially farmer organisations, civil society and private sector - were largely excluded and more efforts are required to effectively engage these groups of stakeholders. For instance, the Malawi 2014 JSR report indicates that the main shortfall of the Agriculture Sector Report which describes the sector's performance in the previous year fails to adequately address activities and issues of non-state actors. The work of the New Alliance and Grow Africa as well as Non-State Actors Coalition provides important platforms for addressing the above shortfall in agricultural sector engagements.

Similar to the intra-government coordination discussed above, some of the salient issues concerning engagements between government and sector stakeholders include the reluctance of officials to share information or resources; their suspicion of the capacity or agendas of non-state organisations or donors; and their inability to appreciate the unique contribution that non-state organisations can make. Conversely, sector stakeholders in some cases are suspicious of government requesting information on their activities. This situation also requires further detailed research to help find workable solutions to facilitate mutual engagement and sharing within the agriculture sector.

In addition, in all four countries, there was growing interest and implementation of structures to engage all agricultural sector stakeholders not previously engaged in various aspects. For example, Malawi and Mozambique are already part of the New Alliance and Grow Africa annual reporting programme which tracks commitments and achievements among various actors, including government, development partners and the private sector. In Zambia and Swaziland, the JSR processes also engaged sector-wide stakeholders including state and non-state actors. The experiences from the implementation of the JSR showed the enthusiasm and commitment by various non-state actors who felt they have been excluded for too long and wanted to make positive contributions in the planning, implementation and evaluation of programmes and policies within the agricultural sector.

\section{Experiences on financial and non-financial commitments}

Financial and non-financial commitments include: budgetary allocations; investments; financial support; capacity building; and organisational commitments made by governments, donors and non-state actors; and key agriculture sector targets, such as growth, productivity and other major results defined in the national agricultural investment plans and other policy and strategic documents. ${ }^{6}$ The experiences on financial and non-financial commitments made by various key stakeholders (government, development partners, private sector, farmer organisations, etc.) indicated that for Zambia and Swaziland, the reported commitments were mainly by government and development partners. In these two countries, involvement of non-state actors regarding making concrete commitments is still lacking and is an area requiring much intervention. On the other hand, Malawi and Mozambique - through their involvement in the New Alliance Cooperation Framework Agreement - experienced substantial commitments and achievements from government, development partners and the private sector., ${ }^{7,8}$

The realisation of financial and non-financial commitments is critical for these countries to achieve their agriculture sector growth and development targets. The failure by an actor to meet their commitments affects successful implementation of agricultural policies and programmes, which affects the final output and impact. From the above experiences, it is clear that more effort is required, especially in non-New Alliance countries such as Swaziland and Zambia, to engage non-state actors to actively and effectively participate in the implementation of agricultural policies and programmes through commitments (both financial and nonfinancial). In Malawi and Mozambique, the focus should be on ensuring that the implementation of the commitments is generating the required impact - that is, the focus is more on the effectiveness of the support provided. Given the growing scarcity of resources for development work, it is critical that the available resources are put to their best available use to generate the greatest impacts in the sector.

\section{Experiences on monitoring and evaluation and development impacts}

The JSR assessments included evaluation of the capacity of the different ministries to implement monitoring and evaluation of agricultural policies/programmes and development impacts. The four countries lack institutionalised monitoring and evaluation capacity to provide regular up-to-date data and analysis of impacts from various agricultural policies/programmes and development impacts. For example, Mozambique, Malawi and Zambia reported that a lack of decentralised data along functional, geographical, sub-sectoral or commodity lines remains a challenge to inform evidence-based planning at lower levels. ${ }^{7-9}$ Overall - in all countries - effective monitoring and evaluation suffers from limited availability of quality data; unreliable or non-existent evaluation of policies/programmes; and limited capacity to apply technical evaluation tools. There has been an increasing emphasis on results from development interventions in recent years. ${ }^{12}$ To strengthen mutual accountability for results and provide evidence-based support to agricultural policy/programme planning and implementation, robust monitoring and evaluation systems are needed in most countries on the continent.

ReSAKSS has made efforts to set up national-level Strategic Analysis and Knowledge Support System (SAKSS) nodes aimed at addressing this gap, and the operationalisation of these nodes is critical for addressing the capacity gap. The SAKSS nodes would help strengthen capacity in strategic analysis, data collection, analysis, knowledge management and sharing among sector stakeholders. However, among the four countries - despite progress made in Malawi, Mozambique and Zambia - there is no operational SAKSS node. In addition, the Ministries of Agriculture themselves lack properly functioning monitoring and evaluation departments or units and rely on outside support, which usually is related to specific programmes as required by the donor.

The agricultural sector JSR processes in the four countries have contributed to the need and implementation of measures to improve monitoring and evaluation in the agricultural sector in the respective countries. For example, Swaziland realised from the JSR processes how a lack of a proper monitoring and evaluation system and structures affects their planning and implementation of agricultural policies and programmes, including how having the same can enhance evidencebased decision-making and implementation. At the time of writing, the Ministry of Agriculture in Swaziland was planning on setting up and operationalising a monitoring and evaluation function that would address the current challenges. In Malawi, for example, the institutionalisation of the annual agricultural JSR process and the subsequent Agricultural Sector Performance Report have helped enhance monitoring and evaluation capacity in the ministry. Further efforts are, however, required to operationalise the country SAKSS node to enhance monitoring and evaluation capacity among other functions.

In terms of performance of the agricultural sector, for the purpose of this paper, we only considered the two priority indicators of the CAADP: attaining at least a $10 \%$ agricultural share of the total national budget to achieve a $6 \%$ annual agricultural GDP growth rate. Various other indicators are presented in the various JSR reports of each country. Figure 1 summarises the agriculture budget in terms of the share of the total national budget for each country. Malawi has consistently achieved the $10 \%$ agricultural budget target since 2008, while Mozambique achieved the same in 2010 and 2014. 
Table 4: $\quad$ Monitoring and evaluation challenges in the four countries

\begin{tabular}{|c|c|}
\hline Country & Monitoring and evaluation challenges \\
\hline Malawi & $\begin{array}{l}\text { Weak monitoring and evaluation at district levels although evidence from the district is used at the national level } \\
\text { Limited capacity to gather data and synthesise information at district levels } \\
\text { Lack of proper information sharing mechanism between the Ministry of Agriculture and Water Development, and partners (other government } \\
\text { ministries, private sector, NGOs, etc.) } \\
\text { Limited availability of quality data and technical analytical capacity to apply evaluation tools, especially at low levels such as at district level } \\
\text { Evaluation usually done by external consultants }\end{array}$ \\
\hline Mozambique & $\begin{array}{l}\text { The national agricultural investment plan (PNISA) fails to provide details of the monitoring and evaluation plan } \\
\text { Besides the overall goals (increasing agricultural sector growth and reducing chronic child malnutrition and hunger) there are no other indicators } \\
\text { defined for measuring progress } \\
\text { Indicators of the PNISA were left to be identified by agencies involved at programme and sub-programme levels and this is yet to be finalised } \\
\text { Lack of decentralised data along functional, geographical, sub-sectoral or commodity lines remains a challenge to inform evidence-based } \\
\text { planning at lower levels }\end{array}$ \\
\hline Swaziland & $\begin{array}{l}\text { Lack of operational monitoring and evaluation system for the agricultural sector } \\
\text { Lack of decentralised data along functional, geographical, sub-sectoral or commodity lines remains a challenge to inform evidence-based } \\
\text { planning at lower levels }\end{array}$ \\
\hline Zambia & $\begin{array}{l}\text { Lack of decentralised data along functional, geographical, sub-sectoral or commodity lines remains a challenge to inform evidence-based } \\
\text { planning at lower levels }\end{array}$ \\
\hline
\end{tabular}

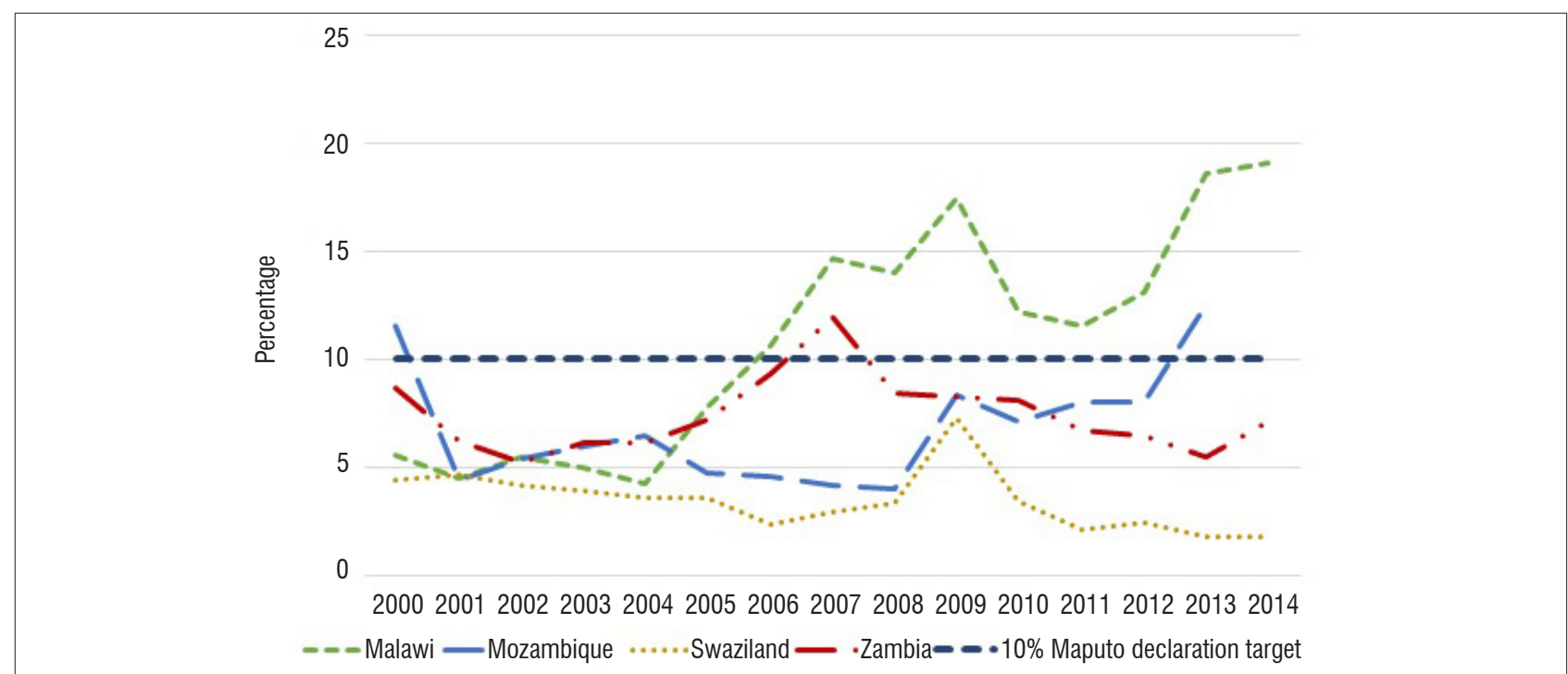

Sources: JSR reports from each country ${ }^{7-10}$

Figure 1: Agriculture percentage share of total national budget.

Zambia has also made some progress in increasing the budget allocation for agriculture. For Swaziland, the invariable low share of the agriculture budget as a component of the total national budget is attributed to various factors, including poor budget execution rates by the Ministry of Agriculture, which, in turn, prompts budget cuts in subsequent years. Another reason is unstable earnings from the Southern African Customs Union, which makes up the largest proportion of the country's revenue. ${ }^{10}$

Despite the progress made in these countries, the main remaining issue is to ensure the quality of the allocation and actual expenditure of the financial resources. All the countries raised concerns regarding ensuring that priority programmes within the national investment plans receive adequate funding from these national agricultural budgets. The JSR report makes it clear that without adequate financial resources allocated to implement priority investment plans in agriculture, the expected development impacts would be difficult to achieve. Therefore, targeted resource allocation to high development priority areas in agriculture would have the greatest impact if the necessary resources are allocated to allow implementation.

\section{Conclusion and recommendations}

The Malabo Declaration's commitment to accountability stresses the continent's resolve to strengthen achievement of results anchored with effective and efficient implementation capacity and optimisation of resources. The CAADP Implementation Strategy and Roadmap identifies the agricultural JSR as the principal instrument for operationalising the mutual accountability framework and reporting on agreed commitments and as a platform to discuss implementation. Our main objective in this paper was to critically assess the experiences of four countries Malawi, Mozambique, Swaziland and Zambia - in the implementation of agricultural JSRs in supporting mutual accountability in Southern Africa. The analysis focused on assessing the lessons learned, challenges experienced and recommendations made for improvement. The key findings and recommendations are summarised below. 
In all the countries reviewed, agricultural policies and/or programmes are still mainly fragmented; however, there are various efforts in each of the countries to harmonise these agricultural policies and programmes. In addition, in cases in which these processes have been completed, the challenge that remains is to effectively bring all stakeholders together in the actual implementation of the policies and programmes. Evidence from the different JSRs in the four countries indicates that the implementation of the CAADP agenda has enhanced stakeholders engagement within the agricultural sector; however, more effort is required to strengthen coordination, especially among government departments. In addition, the realisation of financial and non-financial commitments is critical for the countries to achieve their agriculture sector growth and development targets. The failure by an actor to meet their commitments affects the successful implementation of agricultural policies and programmes, which ultimately affects the final output and impact.

Despite progress in the countries to strengthen mutual accountability, monitoring and evaluation capacity remains a concern, especially at low levels of government. This concern is also linked to the lack of reliable and good quality data at these levels. More efforts are required to strengthen monitoring and evaluation and ongoing efforts in each country should be upscaled. This effort is critical to provide quality, evidence-based support to agricultural policy/programme planning and implementation. The efforts by ReSAKSS to set up national-level SAKSS nodes aims to address this gap, and the operationalisation of these nodes is critical for addressing the capacity gap. The SAKSS nodes would help strengthen capacity in strategic analysis, data collection, analysis, knowledge management and sharing among sector stakeholders.

The recent efforts to conduct JSR assessments in the countries have raised the quest for increased accountability for action and results and each country is implementing measures to improve on these aspects. It is therefore important to note that, although the JSR assessment activities are not the only reason for increasing efforts to ensure mutual accountability, they have really contributed to strengthening ongoing efforts in these countries. In addition, the overall CAADP mutual accountability process and implementation of the CAADP agenda in the respective countries have gone a long way in facilitating sector-wide engagement of stakeholders in planning, implementation, and monitoring and evaluation of agricultural policies and programmes. CAADP mutual accountability is critical to ensure effective implementation and realisation of development impacts of agricultural priorities in the national agricultural investment plans.

\section{Acknowledgements}

We are grateful for support from the International Food Policy Research Institute and ReSAKSS Africa-wide for facilitating the implementation of agriculture JSRs conducted by ReSAKSS Southern Africa in the study countries.

\section{Authors' contributions}

C.N. conceptualised the article content and compiled the first draft. G.M. and S.N. revised the manuscript and made conceptual contributions.

\section{References}

1. Working Party on Aid Effectiveness. Aid effectiveness. A Progress Report on Implementing the Paris Declaration. Paris: OECD/DAC; 2008.

2. Development Assistance Committee (DAC), Organisation for Economic Cooperation and Development (OECD). Paris Declaration on Aid Effectiveness. Paris: 0ECD/DAC; 2005.

3. Development Assistance Committee (DAC), Organisation for Economic Cooperation and Development (OECD). 2008 Survey on monitoring the Paris Declaration. Effective aid by 2010? What it will take. Paris: OECD/DAC; 2008.

4. African Union Commission. Implementation strategy and roadmap to achieve the 2025 vision on CAADP. Addis Ababa: African Union; 2015.

5. African Union Commission. Malabo declaration on accelerated agricultural growth and transformation for shared prosperity and improved livelihoods. Addis Ababa: African Union; 2014.

6. Regional Strategic Analysis and Knowledge Support System (ReSAKSS). Facilitating improved joint sector review (JSR) processes and report at country level. JSR Support Memo. Addis Ababa: ReSAKSS; 2015.

7. Government of Malawi. Malawi agriculture joint sector review (JSR) assessment report. Lilongwe: Ministry of Agriculture and Water Development; 2014.

8. Government of Mozambique. Mozambique agriculture joint sector review (JSR) assessment report. Maputo: Ministry of Agriculture; 2014.

9. Government of Zambia. Zambia agriculture joint sector review (JSR) assessment report. Lusaka: Ministry of Agriculture and Livestock; 2015.

10. Government of Swaziland. Swaziland agriculture joint sector review (JSR) assessment report. Mbabane: Ministry of Agriculture; 2015.

11. Holvoet $\mathrm{N}$, Inberg L. Joint sector reviews - M\&E experiments in an era of changing aid modalities: Experiences from JSRs in the education sectors of Burkina Faso, Mali and Niger. Public Admin Devel. 2009;29(3):204-217. https://doi.org/10.1002/pad.538

12. White $H$. An introduction to the use of randomised control trials to evaluate development interventions. J Dev Effect. 2013;5(1):30-49. https://doi.org/1 $0.1080 / 19439342.2013 .764652$ 